\section{$\underset{\substack{\text { hommes } \\ \text { \& migrations }}}{ }$}

\section{Hommes \& migrations}

Revue française de référence sur les dynamiques

migratoires

$1324 \mid 2019$

Religion et discrimination

\title{
Jodi Picoult, Mille petits riens
}

Traduit de l'anglais (États-Unis) par Marie Chabin, Paris, Actes Sud, 2018, 588 p., $23,50 €$

\section{Mustapha Harzoune}

\section{(2) OpenEdition}

\section{Journals}

Édition électronique

URL : https://journals.openedition.org/hommesmigrations/8712

DOI : 10.4000/hommesmigrations.8712

ISSN : 2262-3353

Éditeur

Musée national de l'histoire de l'immigration

Édition imprimée

Date de publication : 1 janvier 2019

Pagination : 224-225

ISBN : 978-2-919040-44-5

ISSN : $1142-852 X$

Référence électronique

Mustapha Harzoune, « Jodi Picoult, Mille petits riens », Hommes \& migrations [En ligne], 1324 | 2019, mis en ligne le 01 janvier 2019, consulté le 08 janvier 2022. URL : http://journals.openedition.org/ hommesmigrations/8712; DOI : https://doi.org/10.4000/hommesmigrations.8712 


\section{Mille petits riens}

Jodi Picoult. Traduit de l'anglais (États-Unis) par Marie Chabin, Arles, Actes Sud, 2018,

592 pages, 23,50 euros.

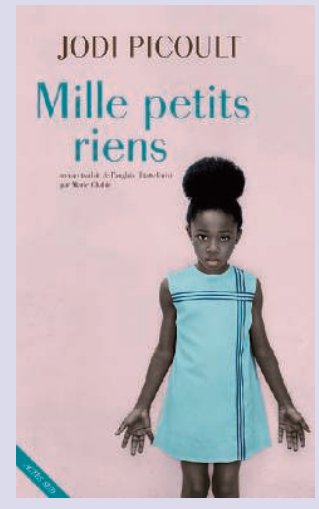

On a beau être une infirmière chevronnée et appréciée, une veuve de guerre courageuse, une mère attentive, s'être éloignée du ghetto pour offrir à son fiston une promesse de vie meilleure, se tenir à l'écart de l'entre-soi; on a beau, depuis les premières classes de l'école, avoir joué le jeu de l'intégration, être «deux fois meilleur», donner des gages, paraître insensible au désarroi collectif..., un jour, «mille petits riens» peuvent vous rattraper, faire écrouler une vie heureuse, bâtie moins sur le mensonge que sur le déni. Car, aux États-Unis, être Noir ne signifie rien. Seul le Blanc serait irréprochable. En un instant, le monde de Ruth va s'écrouler.

Un matin, un comme des milliers d'autres, Ruth prend son service. Elle donne les premiers soins à un bébé né dans la nuit et à sa mère. L'attention du père pour les siens ne parvient pas à masquer l'extrême 
tension qui règne dans la pièce. Et pour cause: Turk et Brittany sont des suprémacistes blancs! Militants radicaux, ils ne supportent pas que cette Noire touche leur fils! Marie, sa supérieure, entérine la volonté du couple. Tout aurait pu en rester là, Ruth aurait pu ravaler sa rancœur, déguiser sa frustration en humour, privilégier son travail, le statut quo et, comme tout un chacun autour d'elle, faire comme s'il ne s'était rien passé. Mais les urgences de l'hôpital conduisent Ruth à devoir surveiller, seule, le nouveau-né. Juste quelques minutes mais, à la clé, la mort du nourrisson. C'est alors que tout bascule. C'est alors que ces milles petits riens, jusque-là invisibles, prennent un sens. Ruth est accusée de meurtre!

Jodi Picoult charpente son récit jusqu'à faire de son lecteur un (heureux) captif, prisonnier de ce cliffhanger aux méthodes dignes des meilleures séries télévisées. Il s'agit bien sûr de racisme, celui lourdingue des suprémacistes blancs, mais surtout celui invisible, sournois, inconscient qui se cache dans ces milles petits riens du quotidien, ces regards, attitudes, mots, réflexes..., en apparence bénins, qui se glissent, structurent, souterrainement, les relations sociales, et parfois amicales. Sans caricatures, trois points de vue rythment le récit: celui de Ruth, celui de Turk et, peut-être le plus important, celui de Kennedy, l'avocate commise d'office, dont le lecteur suit les transformations à mesure que s'approfondit sa relation avec Ruth. En toile de fond, deux univers professionnels et surtout deux fonctionnements institutionnels: celui de la justice (avec le procès et sa préparation) et la santé.

Les quelques bémols possibles (rares répétitions ou ce final qui transporte le lecteur des années après le drame) relèvent du détail: le livre de Jodi Picoult est une réussite et son propos dit, révèle ce qui structure, depuis les institutions jusqu'au tréfonds des mentalités et des imaginaires, la société américaine en matière de relations interraciales.

L'étonnant maintenant: Jodi Picoult, auteure à succès, n'est pas Noire. "Je ne savais pas ce que c'était de grandir dans la peau d'un Noir dans ce pays. Qu'est-ce qui m'autorisait à écrire sur une expérience que je n'ai pas vécue?» Sa réussite tient au fait qu'elle n'écrit pas «à la place de»ou «au nom de». Elle écrit pour montrer comment et quand «les pensées racistes» noyautent les imaginaires, les attitudes, les comportements, l'organisation collective d'une société. Elle écrit dans le droit fil de cette citation de Benjamin Franklin, placée en exergue: «La justice ne pourra être équitablement rendue tant que ceux qui ne sont pas concernés ne s'indignent pas avec ceux qui le sont. » Aux États-Unis, mais rien n'interdit d'élargir le cercle.

M. H. 